\title{
PHRONESIS AND ADVERSE CHILDHOOD EXPERIENCES OF SOCIAL WORK STUDENTS
}

\section{Glynnis Dykes}

Lecturer, Department of Social Work, University of the Western Cape gdykes@uwc.ac.za

\begin{abstract}
This article examines the relevance of (Aristotelian) phronesis (Breier, 2007), denoting practical wisdom, in an attempt to respond to the question: How can phronesis assist in understanding and teaching social work students with adverse childhood experiences (ACEs)?

This article foregrounds family-of-origin experiences of a cohort of social work first year students published previously (Dykes, 2011) exploring identity formation in an assignment entitled: Who am I?" In Dykes (2011) students had been required to reflect family and social issues that had shaped their lives. Approximately 33 (34\%) students had volunteered their assignments. The overall outcome had been to explore themes from the initial data emanating from students' childhood experiences. The first objective explored the implications of ACEs for the professional requirements of social work practice (Dykes, 2011).

In this article the researcher broadened the discussion to focus on a second objective which is to explore the ACEs of social work students and the significance of the concept of phronesis in the ACEs of students being trained as social workers.
\end{abstract}

Key words: adverse childhood experiences (ACEs), counter-transference, narcissism phronesis, reflection, self-awareness 


\section{INTRODUCTION}

There is some concern expressed internationally (Tam, Coleman and Boey, 2011; Gibbons, Bore, Munro and Powis, 2007; Lafrance, Gray and Herbert, 2004) and locally (Schenck, 2009; Earle, 2008) around the professional competencies of newly qualified social workers. Indeed some of these concerns arise during social work training of students (Schenck, 2009; Earle, 2008).

As a social work lecturer, the researcher also became concerned about the disposition of some social work students. The concern was related to an increased awareness of the personal struggles of students and the impact these may have had on their ability to focus on issues that were very similar to their own struggles. This apparent struggle, to separate client issues from their own, could lead to counter-transference within a professional relationship.

In an endeavour to uncover the personal struggles of students, the researcher undertook a study with first year students at the University of the Western Cape (UWC) using an assignment 'Who am I' in a theory module. The research results were published using resilience as conceptual framework (Dykes, 2011). An overwhelming number (73\%) of student participants reflected traumatic events during their childhood (known as adverse childhood experiences). Findings reflected in-depth emotions and trauma but also substantive resilience. However, residual feelings emanating from their traumatic experiences and the role they may play in professional social work competencies form the basis of concern. Although the sample was small, the results did support the stereotype that social workers enter the profession based on their personal struggles (Lafrance et al., 2004). This seems not to be unusual though since many people find meaning in helping others after a trauma (McMillen, 1999).

Personal struggles in one's formative years reflect negative, often traumatic incidences during childhood. These incidences could include the following: physical abuse/neglect; emotional abuse/neglect; exploitation; sexual abuse; rape; abandonment; absent caregivers; caregivers who are/have been substance abusers, involved in criminal activities, mentally ill, suicidal (attempts/ideation), and/or in poverty-stricken circumstances (Dykes, 2011; Brown, Anda, Felitti, Edwards, Malarcher, Croft and Giles, 2010; Ness, 2009). 
International research found that social work students reported a higher incidence of early-life trauma (adverse experiences not limited to childhood only) than other student participants (Olson and Royse, 2006; Lafrance et al., 2004; Black, Jeffreys and Hartley, 1993). In South Africa, Schenck’s (2009) research focused on the socio-economic circumstances of social work fourth year students at the University of South Africa (Unisa) that impacted on their throughput rate. This study related to a similar study undertaken by Earle (2008) who studied early life experiences of social work students at the Universities of Limpopo and Stellenbosch. In both studies, a high proportion of students reported early traumatic experiences.

Olson and Royse (2006) and Lafrance et al. (2004) identified ways in which adverse experiences may affect professional behaviour. In terms of 'the wounded healer' explanation, the following are pertinent: distorted dimensions of empathy (i.e. over-identification with client's issues leading to bias and subjectivity, and working out co-dependency needs on clients), and counter-transference. In terms of more serious ethical misconduct issues, possibilities include sexual boundary violations and distorted assessment of client situations and decision making.

Tam and Coleman (2009:47) defined professional suitability as a "good understanding of social work knowledge, skills, and values and the performance of appropriate behaviours in given practice situations." The assessment of professional suitability is the outcome of the educational process. However, the focus should be on students during social work training. In terms of professional suitability, Lafrance et al. (2009) cited by Gibbons et al. (2007), identified two characteristics (amongst others) to note: Students need to demonstrate, firstly, that they have resolved the impact of personal life experiences (also see Tam, Coleman and Boey, 2011), and, secondly, that they lack narcissism or self-absorption when engaging with others (in social work, viewing the client's situation from a self-centred perspective). Both characteristics are required to minimise countertransference and are thus pre-requisites for social work education and professional practice.

The research problem centres on the impact that personal challenges of social work students may have on their ability to conduct themselves professionally when engaging with clients. The crux of the problem lies in the impact of ACEs on students in social work training during teaching and learning activities, exercises and discussions on issues closely related to their own personal struggles. However, there appears to be insufficient research undertaken in South Africa regarding the role that ACEs may play during the 
training of students for social work and the use of phronesis in making sense of ACEs for social work training. It therefore points to the responsibility on the training institution and the social work programme during students' training and shaping of the professional.

The research question encompasses the following: How can phronesis assist and guide in teaching social work students with ACEs? In order to address this question the following research objectives were established: To explore and describe -

- The ACEs of first-year social work students at UWC.

- The implications of ACEs of students during social work training using phronesis as framework.

\section{CONCEPTUAL FRAMEWORK}

This study will be looking at the research findings through phronesis (developed by the Greek philosopher Aristotle), which means practical wisdom, as conceptual framework for analysis.

Why phronesis? Phronesis reflects the dualism of personal development through formal learning endeavours and through life experiences. This concept is especially relevant, firstly as a framework for discussion on adverse childhood experiences and the role these may play in the lives of student participants; and secondly in view of the often negative stance towards the role of experience in learning by conservative educational approaches.

In classical Greek philosophy and science, Aristotle developed the concept of phronesis in his Nicomachian Ethics Book VI, 1797-1808 (Back, 2002). Aristotle distinguished between theoretical and practical knowledge. Theoretical knowledge refers to the question "what exists?" which means an ordered and pre-existing system of principles that explains phenomena in a specific field. According to Back (2002), when reference is made to various fields of information it is called episteme (knowledge) and when reference is made to the basic sciences such as mathematics, it is called sophia (wisdom). In theoretical knowledge we use our sense and intellect to decipher. Practical knowledge gives rise to the question "what must I do"? This presupposes an action that is morally sound. In terms of practical knowledge, Aristotle also distinguished between techne (skill) and phronesis (practical wisdom) (Back, 2002). 
Aristotle's theory of phronesis has experienced a revival as an opposing perspective to the modernist over-dependence on technological rationalisation (Tabachnick, 2004; Back, 2002). For Aristotle, phronesis is neither cleverness nor technical skill (techne), it is an ethos (disposition or attitude) based on previous experience and understanding and is used on those occasions when no prior or pre-existing rule is available to act or make decisions (Gallagher, 1993). In distilling the key characteristics of phronesis, Breier (2007), Tabachnick (2004) and Gallagher (1993) provided the following:

- Phronesis is education gained through life events (life experiences).

- Phronesis requires time for experience to develop and to be used. It is slow-paced.

- Phronesis requires virtue - acquiring the right habits (an ethos), which Jean-Francois Lyotard describes as "pedagogy of the soul" (Gallagher, 1993:300).

- Phronesis requires action within a specific context. Action is determined by the context or situation in which the event is played out.

- Phronesis gazes outwards to the wider community beyond the self.

Breier (2007) and Back (2002) apply phronesis to the practice of teaching. According to Back (2002), Aristotle saw the practice and process of teaching as techne, however, knowledge of the various disciplines to be taught would fall under episteme, as well as theories of education. The above authors viewed the wisdom of teachers not as being classroom-based learning but as being developed through "the knowledge and competencies of everyday life" (Breier, 2007:100). These are "learned inductively" from the bottom up (Back, 2002).

\section{RESEARCH METHODOLOGY}

Philosophically, this research is underpinned by the ideas in the social constructivist world view (Creswell, 2009) or as identified by Babbie and Mouton (2006) as the phenomenological/interpretist tradition. In this view, persons seek understanding of their experiences. The qualitative research approach emanates from the social constructivist world view and will link with the research question and objectives of this study. According to Creswell (2009:4), "qualitative research is a means for exploring and understanding the meaning individuals or groups ascribe to a social or human problem” (also see Babbie and Mouton, 2006:270). 
The researcher selected the case study research design as an appropriate means of achieving the research goal and objectives. Case study research consists of the study of an issue by means of one or more cases within a particular context (i.e. a South African university) (Creswell, 2007; Babbie and Mouton, 2006). Individuals form the unit of analysis (students) and the point of focus is on orientations, for example, attitudes, beliefs, values, prejudices and predispositions (Babbie and Mouton, 2006).

\section{Sampling}

Students were drawn from a theory module in the first year curriculum which the researcher teaches. In this module there are two areas of focus: firstly the major social challenges within the South African context; and secondly the different fields of practice that link with these major social challenges. In a reflective written assignment entitled: "Who am I?" students are required to reflect who they are; how they have developed; what social events and issues have impacted on their development in their opinion. Thirty-three (34\%) students had volunteered their assignments for the initial research, which reflected a non-probability, criterion sample.

\section{Data analysis}

According to De Vos (2007:333), “data analysis is...the process of bringing order, structure and meaning to the mass of collected data." The researcher will use the descriptive and interpretative approach that reports on the opinions and the socio-cultural events in the lives of the respondents (Ritchie and Lewis, 2005). This is an important choice as it links with the main focus of the research, which is to understand and report on the adverse childhood experiences of student participants. The initial research was analysed using Creswell's approach (2009), dividing the data into topics, themes and subthemes. Here the data has been summarised into the main topics.

\section{DISCUSSION OF FINDINGS}

The participants had reported several factors that had impacted on their lives and their experiences during their formative years. From the data four broad topics were discerned and originally published by Dykes (2011). The four broad topics were: (1) adverse childhood experiences; (2) a negative social environment; (3) the impact of adverse childhood experiences on participants; and (4) positive outcomes of the ACEs. The four topics are summarised as follows: 


\section{Topic 1: Adverse childhood experiences of participants}

Student participants reported amongst others, the following: death of one or both parents; troubled family relationships; absent caregivers; financial struggles; and child abuse. These reflected the kinds of negative and traumatic early life experiences that the participants had endured.

"In my mind I felt unwanted and not loved. Then I (sought) brotherly love outside of our home. I started to make lots of different kinds of friends... I decided to stick to the friends who like to party and be disobedient."

Troubled family relationships signify that family members are not able to meet each other's needs, as they are unable to communicate meaningfully with each other (Bezuidenhout, 2004). Jekielek (1998) asserts that both marital conflict and marital disruption impact on the emotional adjustment of children who then later develop anxiety, depression and social withdrawal.

Family financial struggles were commonly cited by student participants. They related how being poor made them feel inferior, as well as constantly hungry and worried about what they were going to eat.

"Till about 11, I had a good life, financially stable. But once my parents started having marriage problems my life drastically changed. I went from wasting food, to saving every last bit and stretching the little we had so that we wouldn't have to go to bed hungry."

Their circumstances forced them into taking up the adult role of earning an income, for example, selling chips and sweets at school sports events and traumatically, enduring sexual abuse for promises of money or "a half of bread".

Child sexual and physical forms of abuse were the most extreme trauma reported by student participants. Sexual abuse largely involved family members as perpetrators and the burden of keeping family secrets.

"There is the day I was raped by an old man ... As a young girl ... I started to cry when it was hurting. I kept that secret since from when I was young up until the present."

"I can't remember being allowed to speak about my feelings, especially that which would bring shame to the family; thus resulting in my silence to the fact that I was being sexually abused for eight years. It would be hard to explain how two highly regarded people in our family would be guilty of this offence." 
Threats surrounding silence and secrecy added to their levels of anxiety. Student participants spoke of their reluctance to bring shame upon their families and of having rather maintained their silence. Bezuidenhout (2004) reported a number of behaviours pertaining to child sexual abuse: bedwetting, increased social withdrawal and isolation, eating disorders, nightmares, suicide attempts, and sexually inappropriate behaviour. As regards physical abuse, student participants spoke of their powerlessness in the light of being physically abused by their care-givers, notably grandparents or aunts or uncles who were placed in charge of their care by absent parents. Student participants spoke of their lack of self-confidence and selfesteem as a result of these abuses.

"My parents passed away in the same year but different months and left us with relatives (uncle) that was how we get abused physically, emotionally and verbally everyday and that resulted in the lack of self-confidence, selfesteem and self-image in my life."

\section{Topic 2: The social environment of participants}

In topic 2, participants explained the social challenges within their communities and identified various social issues. Kirst-Ashman and Hull (2002:308) define the social environment as being "the conditions, circumstances, and human interactions that encompass human beings". Participants particularly identified crime, unemployment, gang activities, rape, drug and alcohol abuse, teen pregnancies and HIV and AIDS.

"Many people are dying of HIV and AIDS. The community believes in traditional healers... that a male with HIV have to sleep with a virgin and will be cured. This makes HIV spread... This increase the high rate of rape because the man with HIV attack the young female."

"A lot of them are depending on the social grants, provided by the government. Because of the joblessness, the crime rate is very high, rape, drug and alcohol abuse, teenage pregnancy."

Participants were also not immune regarding the danger of living in these communities. The exposure to these social circumstances placed participants at risk of, for example, substance usage, youth offences, school dropout, teen parenthood and early violent death (Kirst-Ashman and Hull, 2002; Myers and Taylor, 1998). These authors assert that children who live in extreme poverty over many years are the most vulnerable to troubled behaviour. Earle (2008) found that "a sizeable portion" of the students in her 
research recounted experiences that mirrored the social challenges facing South Africa (in Schenck, 2009).

\section{Topic 3: The impact of ACEs on participants}

Teen substance abuse; teen suicide attempts or ideation and teen parenthood characterised topic 3, but also characterised the way the student participants felt about themselves. Student participants' troubled behaviour seemed to have been precipitated by two main factors: firstly, adolescence, which is generally regarded as the time for experimentation and risk-taking behaviour.

"As a teenage girl I was also affected by teenage pregnancy. At the age of 16 years I was pregnant after everything my mother has been through... I had to drop out of school and look after my baby."

"When I returned from the bush I impregnated one of my girlfriends and that was a disappointment to my grandmother."

Secondly, anger and self-loathing reported by participants also precipitated their troubled behaviour. These emanated from feelings of being unloved and rejected (within the family) as well as the impact of labelling and racism (external to the family).

"I started looking at the world in a different way. I resented the fact that I was black if it meant that I had to live the way she was living and I hated my parents for dying and leaving me in this sick world."

"I was also told how fat I was and that nobody like me, this was a very painful period in my life. It hurt me so much that I started hating myself and not being able to look at myself in the mirror everyday. I developed a low self-esteem and low self-confidence."

Participants reported drug taking although this behaviour did not feature strongly. One participant described himself as having an "addictive personality" and had the propensity "of pushing the limits". Some also became involved in early sexual relationships and subsequently became youthful parents. These students reported the emotional consequences of being teen parents and the impact on their families. Extreme hopelessness manifested in three participants attempting suicide; with two of them having made multiple attempts.

"After many attempts to end my life ... I realised that I had a debt unto myself to achieve greatness and to help others." 
"I very, very nearly lost my life a few times because of wanting to commit suicide. I had nothing! I reached rock bottom."

Furthermore, students reflected on their "emotional baggage"; poor home circumstances; their relationships with their parents; and financial burdens of family as factors that would influence their studies and their future. In terms of emotional factors a high number of participants cited their lack of self confidence and self-esteem as areas of concern. They were also concerned about their parents' financial struggles (at home) and their worry that they would not be able to pay their way and to meet their basic needs. Additionally, students expressed their worry about how things were going back home. They admitted that these factors forced their attention away from their studies.

"Burdens to me this year would be my financial problems. Sometimes I don't even have travelling money. ... My mom's single and struggling to find employment. This has a down side 'cause my focus is divided."

"The one thing that will be a huge burden for me this year is the fact that I don't have financial aid and my parents will have to pay my fees for this year...Now I have to be worried about putting my parents in debt."

Schenck (2009) states that the throughput rate of social work students is particularly hampered by students' personal home circumstances and trauma.

\section{Topic 4: Positive outcomes}

In topic 4, students reflected on their personal competencies and skills; resilience; spiritual strength; and family support. There was a strong response to volunteering and being involved in their communities. This is a reflection of wanting to contribute to the fulfilment of others.

"I was involved in organisation called Treatment Action Campaign which is fighting for the rights of HIV and AIDS people."

"My friends and I volunteer in a shelter, where we bathed, fed and helped young children with their homework."

In their study, Masten, Best and Garmezy (1990) concluded that one of the characteristics of children who have recovered positively from trauma is that they have areas of competence and efficacy valued by themselves and others. In addition, they are good learners and problem-solvers. Participants also told of family support which served as motivation and fostered resilience. Positive caregiving can mitigate the effect of adverse experiences (Egeland, Carlson 
and Sroufe, 1993). Some participants (51\%) cited their religious beliefs as a source of strength which gave them the impetus to do good and help others.

"I was so strong and patient because I knew that God was on my side."

"The only thing that kept me going and on my toes was my family and church."

McMillen (1999) confirms that adverse experiences can result in changes in one’s 'existential outlook' through religion and spirituality.

\section{PHRONESIS AND THE ACES OF SOCIAL WORK STUDENTS}

Research objective 1 required the focus on exploring the ACEs of student participants as first year social work students. The data in Topic 1 reflected the ACEs of student participants who mostly lived in a social environment (Topic 2) that further compromised the quality of their lived experiences. These experiences satisfied the definitional elements of ACEs from which further aspects could be explored. Topics 3 and 4 both reflected outcomes of enduring ACEs that emerged from the "Who am I?" essays.

Research objective 2 required the focus on exploring the implications of ACEs of students during social work training through the use of phronesis as framework. If we use the five definitional elements of phronesis we can explore the responses of student participants more deeply:

\section{Phronesis is education gained through life events}

This element is a positive interpretation of the ACEs of student participants, indeed of the human experience. It says that we do not go through life merely as spectators but become transformed through these experiences. Through enduring these traumatic experiences told by participants, the focus is how they had learned (benefitted) from these events. These are not positive incidents but certainly life changing in many cases. Generally there are positives and negatives attached to life experiences. The positives derived from these experiences are of particular importance for social work students, for example, resilience, insight, empathy, a helping nature and hope (amongst others). It shows extraordinary depth and resilience for an individual to rise up from these incidents and want to "help others: (i.e. choosing social work as career). This then links to topic 4 relating to participants' personal competencies and strengths which propelled them forward. It can also link with Markus and Narius' (Van Breda, 2010) argument that we are motivated by dreams of a possible 'future self' which can have a positive influence on 
our present decision making and behaviour. However, Van Breda (2010) does caution that particular socio-economic circumstances can constrain our dreams of a 'future self'. Our circumstances can either produce idealistic or undeveloped possible selves which could then have a skewed effect on the student participants' behaviour.

McMillen (1999) also cautions that not everyone will derive benefit from adverse experiences. The severity of the impact will depend on the following: the severity of the incident; age; social support; coping skills; and characteristics of the person

\section{Phronesis requires time for experience to develop and to be used}

This factor is a challenging one since most students matriculated the year prior to entering university. Most of these students might not have the maturity yet to have made sense of their experiences. Hence Lafrance et al. (2004) assert that it may well be unreadiness and not unsuitability that may contribute to the concerns raised around (future) ethical conduct and practice competence.

\section{Phronesis requires virtue - acquiring the right habits (an ethos)}

This element seems to form the crux of social work educators' concerns. Some student participants generally could not yet show the ethos or disposition required for professional practice which could be ascribed to being in their first year of study and/or their youth. In this way it may well be linked to the previous element and discussion on readiness for social work educational requirements. A vital ingredient in virtue is 'acquiring' rather than 'having' already. Acquiring the right habits in professional helping points to social work education, but also requires a positive jumping-off point as scaffold.

Topic 4 (positive outcomes) can represent the jumping-off point. Linley (2003) and McMillen (1999) confirm that enduring a traumatic experience can play a role in jumpstarting an individual's capacity to do something good for the next person. It suggests that one has derived something from the experience. Linley (2003) equates this to wisdom with the added dimension of moral goodness (which we can link to phronesis). Moral goodness can be seen as living a life that is fulfilling but also possibly contributes to the fulfilment of others. Students' desire to contribute to their respective communities by volunteering showed one source of moral reasoning and goodness based 
on their religious beliefs. This characteristic also forms the basis of citizenship (also aligned to a UWC graduate attribute).

\section{Phronesis requires action within a specific context}

Phronesis indicates an attitude or disposition 'when no prior or pre-existing rule is available to act or make decisions' (see page 335). The previous element is also relevant in terms of ethos. Here it asks that we use our notion of what constitutes ethical behaviour to make a decision or act. Regarding social work education and practice requirements, much of what we expect is based on this premise. We cannot teach the depth of ethical behaviour; however, we can set the groundwork on which students must base their future conduct. Teachers can often make an assumption that all students have had positive role models that demonstrated ethically sound behaviour and therefore should know how to act/behave. The ACEs of participants have shown that this is not always the case. From students' responses, they have had care-givers (within family context) who have often betrayed their trust through neglect, abuse or being absent.

\section{Phronesis gazes outwards to the wider community beyond the self}

Students reflected some of their decision-making and choices through volunteering and participating in the addressing of social issues. Their responses reflected a strong religious base that also formed the motivation to contribute to their world that is connected to thriving (Dowling, Gestsdottir, Anderson, von Eye, Almerigi, and Lerner, 2004; Linley, 2003).

The research question required the focus on the role of phronesis in teaching social work with ACEs. Phronesis allowed for the dissection of the data through a different lens. Through phronesis we learnt that students' experiences could have positive repercussions as they can be a means to personal growth and development. This development is however gleaned over time as we make sense of our experiences and learn to contextualise them. Thus it may come with maturity and would require positive habits or disposition for ethical decision making and behaviour. Not all students would fulfil all the elements of phronesis, however. It would depend on the impact of ACEs and the time needed for recovery and resilience to be developed. This recovery is highly individualised since trauma and stress induced by adverse events impact on the whole person ('feelings, thoughts, values, emotions, behaviour') (Wade and Schenck, in press). 
The aftermath of enduring ACEs represented participants' practical knowledge (phronesis). The question now is how we as social work teachers make decisions and choices relevant to the context and practical knowledge of students? How do we assess (value) not only practical experience from the everyday but also the moral judgement and reasoning in the action or decisions made?

According to Aristotle (Back, 2002) moral behaviour cannot be taught but must be experienced or modelled by others (also teachers). Aristotle asserts that in considering good modelling of phronesis we should think about whom we would consider as being "practically wise" (Breier, 2007:102). In this way Back (2002) posits reflective practice as a means to develop practical wisdom. Another means to develop practice wisdom comes from KirstAshman (2013) who recommends critical thinking perspectives. This means questioning the "beliefs, statements, assumptions, lines of reasoning, actions and experiences" not only of the client but also of yourself as the social worker (Kirst-Ashman, 2013:xix).These have implications for social work curriculum design and the kinds of teaching and learning activities that can allow students to explore, reflect and learn moral behaviour and judgement.

The focus should be on learning opportunities for students to create or build on their capacity and willingness for self-awareness (Lafrance et al., 2004). Hancock (1997) confirms that an ingredient of professional helping is the need for self-awareness by the social worker. Students must be assisted to become aware of the impact of ACEs on themselves emotionally and socially. In addition, they must learn and be taught of the relationship that may exist between their experiences, social work professional relationships and competencies, and the construction of their 'personal values, beliefs and attitudes (Lafrance et al., 2004).

Learning opportunities should assist students to concretise their experiences juxtaposed with social work requirements, such as counter-transference for example, or to uncover their strengths and positive traits. In this way, a departure from the 'wounded healer phenomenon' can be facilitated. For example, each year level can provide scaffolding for learning within theory and practice modules to teach students to critically reflect and identify their values and attitudes. Students will thus incrementally discover their social work disposition (i.e. Insightfulness, sensitivity and empathy), values and principles (particularly principles required of the social worker in the professional use of self such as beliefs, opinions and values, self-perception) and skills (i.e. relating and engaging with clients, or effective coping strategies) (Lafrance et. al., 2004; Hancock, 1997). 
In addition strong linkages should be made with the university's resources for opportunities for personal healing through the processing and integration of past experiences.

\section{CONCLUSION}

The ACEs of social work participants demonstrated the adverse and often traumatic experiences endured during their childhood, the most vulnerable phase of human development. Students bring their experiences into the social work classroom and the concern was that these would possibly extend beyond the classroom into professional practice. The conclusion is that the most appropriate time for assisting students would be during their social work training. Phronesis allowed for an increased awareness of the implications of ACEs and how these should be addressed within the social work curriculum. The precursor was an acceptance that ACEs could be affecting the majority of social work students and that the impact on the student should not be ignored. The social work curriculum can provide many learning opportunities for students to appropriately position their experiences as a scaffold in their training into becoming insightful and empathic professional social workers. These learning opportunities need to be further researched.

\section{REFERENCES}

Babbie, E. and Mouton, J. (2006). The Practice of Social Research (South African Edition) Cape Town: Oxford University Press.

Back, S. (2002). “The Aristotelian Challenge to Teacher Education” History of Intellectual Culture 2(1) ISSN 1492-7810.

Bezuidenhout, F. (2004). A Reader on Selected Social Issues Pretoria: Van Schaik Publishers.

Black, P., Jeffreys, D. and Hartley, E. (1993). "Personal History of Psychosocial Trauma in the Early Life of Social Work and Business Students” Journal of Social Work Education 29(2):171-180.

Breier, M. (2007). "Recognising Phronesis or Practical Wisdom in the Recognition (Assessment) of Prior Learning” paper presented at the $5^{\text {th }}$ International Conference of Researching Work and Learning Cape Town, December 2007. 
Brown, D., Anda, R., Felitti, V., Edwards, V., Malarcher, A., Croft, J. and Giles, W. (2010). "Adverse Childhood Experiences are Associated with the Risk of Lung Cancer: A Prospective Cohort Study” BMC Public Health 10(20), www.bio-medcentral.com/1471-2458/10/20

(Accessed on 01/10/2010).

Creswell, J. (2007). Qualitative Inquiry and Research Design: Choosing Among Five Approaches California: Sage Publications, Third Edition.

Creswell, J. (2009). Research Design: Qualitative, Quantitative and Mixed Method Approaches California: Sage Publications, Third Edition.

De Vos, A. (2007). “Qualitative Data Analysis and Interpretation” in De Vos, A., Strydom, H., Fouche, C. and Delport, C. Research at Grassroots: For the Social Sciences and Human Service Professions Pretoria: Van Schaik Publishers, Third Edition.

Dowling, E., Gestsdottir, S., Anderson, P., Von Eye, A., Almerigi, J. and Lerner, R. (2004). "Structural Relations Among Spirituality, Religiosity and Thriving in Adolescence” Applied Developmental Science 8(1):7-16.

Dykes, G. (2011). "The Implications of Adverse Childhood Experiences for the Professional Requirements of Social Work” Social Work/Maatskaplike Werk 47(4):521-533.

Earle, N. (2008). Social Work in Social Change: The Profession and Education of Social Workers in South Africa Cape Town: HSRC.

Egeland, B., Carlson, E. and Sroufe, L. (1993). "Resilience as Process" Development and Psychopathology 5(4):517-528.

Gallagher, S. (1993). "The Place of Phronesis in Postmodern Hermeneutics" Philosophy Today (37):298-305.

Gibbons, J., Bore, M., Munro, D. and Powis, D. (2007). Using Personal Quality Assessment for Selection of Social Work Students Australian Social Work 60(2):210-221.

Hancock, M. (1997). Principles of Social Work Practice: A Generic Practice Approach New York: The Haworth Press. 
Jekielek, S. (1998). "Parental Conflict, Marital Disruption and Children’s Emotional Well-being” Social Forces 76(3):905-935.

Kirst-Ashman, K. (2013). Introduction to Social Work and Social Welfare: Critical Thinking Perspectives Canada: Brooks/Cole Cengage Learning, Empowerment Series, Fourth Edition, International Edition.

Kirst-Ashman, K. and Hull, G. (2002). Understanding Generalist Practice California: Brooks/Cole, Third Edition.

Lafrance, J., Gray, E. and Herbert, M. (2004). "Gate-keeping for Professional Social Work Practice” Social Work Education 23(3):325-340.

Linley, P. (2003). "Positive Adaptation to Trauma: Wisdom as Both Process and Outcome” Journal of Traumatic Stress 16(6):601-610.

Masten, A., Best, K. and Garmezy, N. (1990). "Resilience and Development: Contributions from the Study of Children Who Overcome Adversity" Development and Psychopathology 2:425-444.

McMillen, J. (1999). "Better For It: How People Benefit from Adversity" Social Work 44(5):455-468.

Myers, H. and Taylor, S. (1998). "Family Contributions to Risk and Resilience in African American Children” Journal of Comparative Family Studies 29(1):215-229.

Ness, C. (2009). "The Adverse Childhood Experiences (ACE) Study". Schuyler Centre for Analysis and Advocacy (New York): Research Briefing.

Olson, C. and Royse, D. (2006). "Early-life Adversity and Choice of the Social Work Profession” Journal of Evidence-Based Social Work 3(2):31-47.

Ritchie, J. and Lewis, J. (Eds.) (2005). Qualitative Research Practice: A Guide for Social Science Students and Researchers London: Sage Publishers.

Schenck, R. (2009). "The Socio-economic Realities of the Social Work Students of the University of South Africa" Social Work/Maatskaplike Werk 45(3):299-313. 
Tabachnick, D. (2004). "Phronesis, Democracy and Technology" Canadian Journal of Political Science 37(4):997-1016.

Tam, D. and Coleman, H. (2009). "Construction and Validation of the Professional Suitability for Social Work Practice Scale” Journal of Social Work Education 45(1):47-63.

Tam, D., Coleman, H. and Boey, K. (2011). "Professional Suitability for Social Work Practice: A Factor Analysis" Research on Social Work Practice, http://rsw.sagepub.com/ (Accessed on 14/10/2011).

Van Breda, A. (2010). "Possible Selves: Group Work with Young People in a South African Township” Practice: Social Work in Action 22(3):181-192.

Wade, B. and Schenck, C. (in press). "Trauma is the 'Stealing of my Sense of Being Me': A Person-centred Perspective on Trauma” Social Work/ Maatskaplike Werk 48(1). 